Volume 11, No.1, January - February 2022

International Journal of Advanced Trends in Computer Science and Engineering

Available Online at http://www.warse.org/IJATCSE/static/pdf/file/ijatcse071112022.pdf

https://doi.org/10.30534/ijatcse/2022/071112022

\title{
Conception of the Sflavar Approach: Classification of Satellite Data
}

\author{
GHERDAOUI Sara ${ }^{1}$, FIZAZI Hadria ${ }^{2}$ \\ ${ }^{1}$ Department of Computer Sciences, University of Science and Technology of Oran, Algeria, \\ sara.gherdaoui@univ-usto.dz \\ ${ }^{2}$ Department of Computer Sciences, University of Science and Technology of Oran, Algeria, \\ hadria.fizazi@univ-usto.dz
}

Received Date : December 12, 2021 Accepted Date : January 13, 2022 Published Date : February 06, 2022

\begin{abstract}
Unsupervised classification is the search for homogeneous groups in a dataset. This problem is therefore of great complexity and the use of approximation algorithms is inevitable. In this regard, we will call upon a system resulting from a vision of collective intelligence inspired by the behavior of frogs as individuals seeking food, collaborating with each other to accomplish tasks that they cannot perform individually. As a measure of optimization we will make a change by integrating other variation operators. This will be applied to a LANDSAT5 TM (Thematic Mapper) satellite image of the ORAN region.
\end{abstract}

Key words: Bio-inspiration, Frog jump algorithm, Satellite image, Unsupervised classification, Variation operators.

\section{INTRODUCTION}

Off the planet, satellites observe our environment. The measurements they record are sent to ground stations; there computers use the information to provide us with images of how the earth works. Specialists can study ozone concentration, wind circulation or the temperature of the atmosphere and oceans. Artificial colors allow bettering distinguishing the movements of the sea the state of the forests or the ripening of the crops, Henceforth no region is inaccessible [1].

These observations will be transformed into images called satellite images, which allow us to watch over the health of the planet will constitute a gigantic knowledge and a new treasure that must be exploited.

Today, satellite images are becoming an essential tool for monitoring, planning and forecasting, but their analysis and processing requires the use of robust and powerful methods.
Many methods have been designed, now metaheuristics are considered more efficient and more suitable for this field and more precisely bio inspired methods [2].

The latter are inspired by biology such as genetic algorithms, artificial immune systems [3], neural networks [4][5]; either ethology such as fly algorithm [6], particle swarms [7], ant algorithm [8]

In this paper, we looked at the frog jump algorithm where the population looks for localities that have a maximum amount of food randomly spread on stones in a pond [9], thus we propose to make changes to this algorithm

\section{FROG JUMP ALGORITHM}

When This algorithm is a metaheuristic method of bioinspired optimization where Each Frog, represents a solution to the problem(Figure 1). The entire frog population is divided into a number of groups of frogs called communities that evolve independently to travel the space of solutions in different directions. Information between different communities flows through a jumping process [10]-[12].

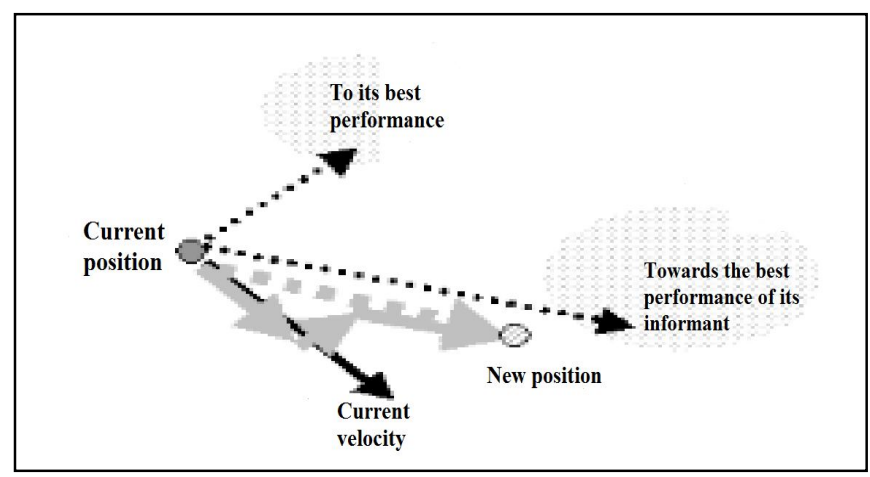

Figure 1: Diagram of principle of frog movement 
Suppose the initial population, consisting of $\mu$ frogs, randomly defined in space $(\boldsymbol{i}=1,2, \ldots, \boldsymbol{\mu})$.

The fitness $f(i)$ of the $\mathrm{I}^{\text {th }}$ frog represents the value of the objective function. All frogs are sorted in descending order and are divided into $\boldsymbol{m}$ communities each containing $\boldsymbol{n}$ frogs $(\boldsymbol{\mu}=\boldsymbol{m} \times \boldsymbol{n})$, so that the first frog belongs to the first community, the second frog is assigned to the second community etc.

In each community, the frogs providing the best $\boldsymbol{X}_{\boldsymbol{b}}$ and the worst solution $\boldsymbol{X}_{\boldsymbol{w}}$.

The frog giving the best solution in the entire population is noted by $\boldsymbol{X}_{\boldsymbol{g}}$.

During the evolution of a community, (local exploration), the worst frog makes a jump to the best $\boldsymbol{X}_{\boldsymbol{b}}$ based on the following rules [13]:

$$
\begin{gathered}
S=\mathrm{R} \times X_{b}-X_{W} \\
X_{W^{\prime}}=X_{W}+S\left(S<S_{\max }\right)
\end{gathered}
$$

Where

$S:$ the value of the jump,

$\boldsymbol{R}$ : a random number between 0 and 1,

$S_{m}:$ the maximum allowable jump.

If the jump improves the solution, then this $\boldsymbol{X}^{\prime}{ }_{w}$ replaces the worst $\boldsymbol{X}_{w}$. Otherwise, the same rule is applied by replacing this $\boldsymbol{X}_{\boldsymbol{b}}$ by $\boldsymbol{X}_{\boldsymbol{g}}$.

If $\boldsymbol{X}^{\prime}{ }_{w}$ is still worse than $\boldsymbol{X}$, then we randomly generate another solution better than $\boldsymbol{X}_{\boldsymbol{w}}$ and replace $\boldsymbol{X}_{\boldsymbol{w}}$ with $\boldsymbol{X}^{\prime}{ }_{w}$. Each community evolves in a number of iterations.

The $\mathrm{m}$ communities are then mixed to re-form the population and the sorting process, partitioning the population into communities, local research and the mixing of communities is repeated until a stop criterion is met (maximum iteration number reached) [14] [15].

The steps of the SFLA algorithm are illustrated by the Figure 2:
Step 1: Set the $\boldsymbol{\mu}$ population size, the $\mathrm{m}$ of community and the $\boldsymbol{N}$ of iterations. Step 2: randomly generate a population of solutions and evaluate each solution.

Step 3: sort the population and determine the best solution $\mathbf{X g}$

Step 4: partition the population into communities

Step 5: local research

For each community, repeat for $N$ iterations:

- Determine the best $\boldsymbol{X}_{\boldsymbol{b}}$ solution and the wrong $\boldsymbol{X}_{w}$ solution.

- Calculate the $\boldsymbol{X}^{\prime}{ }_{w}$ solution from $\boldsymbol{X}_{\boldsymbol{b}}$

- If $\boldsymbol{X}^{\prime}{ }_{w}$ is better than $\boldsymbol{X}_{\boldsymbol{w}}$ replace $\boldsymbol{X}_{\boldsymbol{w}}$ with $\boldsymbol{X}^{\prime}{ }_{w}$

- Otherwise calculate $\boldsymbol{X}^{\prime}{ }_{w}$ from $\boldsymbol{X}_{g}$ and change $\boldsymbol{X}_{w}$ to $\boldsymbol{X}^{\prime}{ }_{w}$

- If $\boldsymbol{X}^{\prime}{ }_{w}$ is better than $\boldsymbol{X}_{w}$

- Otherwise randomly generate $\boldsymbol{X}^{\prime}{ }_{w}$ and replace $\boldsymbol{X}_{\boldsymbol{w}}$

- End if

Step 6: regroup the $\mathrm{m}$ communities to train the population again

Step 7: Go to Step 3 if the stop criterion is not met

Figure 2: SFLA algorithm

\section{VARIATION OPERATORS USED}

Frogs can improve by communicating with each other (by passing information), which is not always verified and can lead to divergence, the reason why we used the evolutionary algorithm variation operators (crossing, mutation and migration) which are considered more efficient [4][16].

\subsection{Crossing}

Because It is important to note that the method of crossing chosen depends on the representation of individuals (in our work the representation is real). Thus, to calculate the new individuals (children) $\mathrm{P} \beta$ it is enough to choose a cut-off point (that is to say a position in the chain) from which the data are exchanged between the two parents.

\subsection{Mutation}

The mutation is the second variation operator used just after the crossing. It consists in modifying the individuals resulting from the crossing.

In the case of a real representation, the simplest way is to add to each individual component a realization of a centered normal law (of zero expectation and standard deviation set by the user).

\subsection{Migration}

Use Migration involves introducing a predefined number of new randomly created $\mathrm{P} \gamma$ individuals into the current population to ensure population diversity. 


\section{SFLAVAR APPROACH DIAGRAM}

The diagram of the SFLAvar approach is as follows (Figure3):

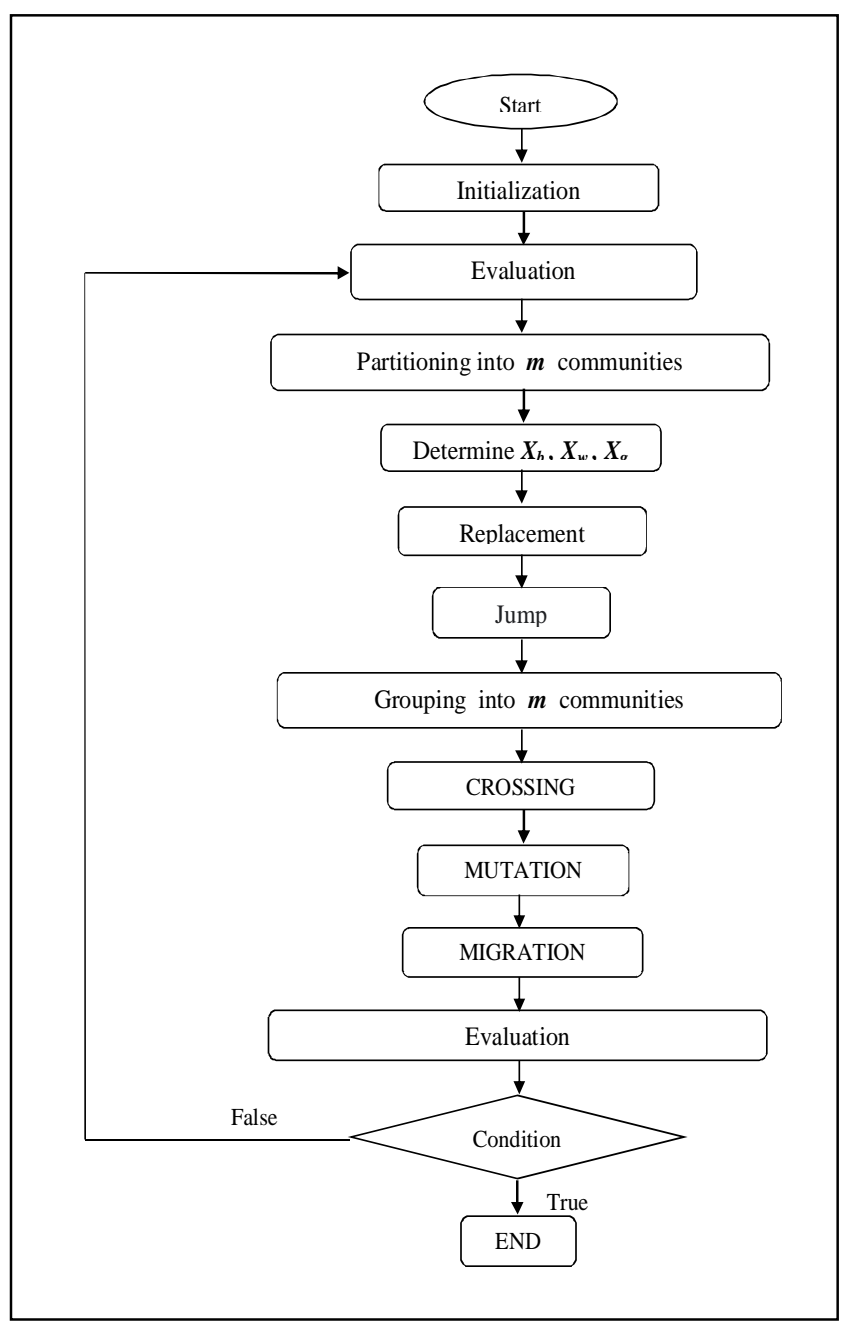

Figure 3: Diagram of SFLAvar

\section{APPLICATION OF THE SFLAVAR APPROACH TO SATELLITE IMAGE CLASSIFICATION}

We will apply our SFLAvar approach to the unsupervised classification of a synthetic image and a satellite image of type LANDSAT5 sensor TM (Thematic Mapper) taken in 2010. The images used are shown in Figure 4 above.

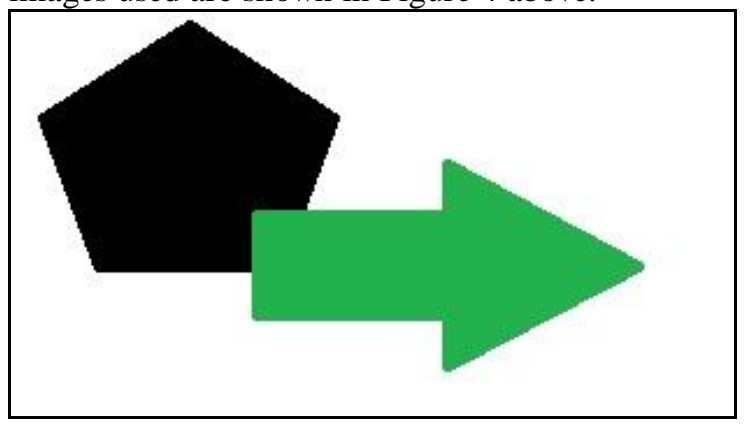

(a)

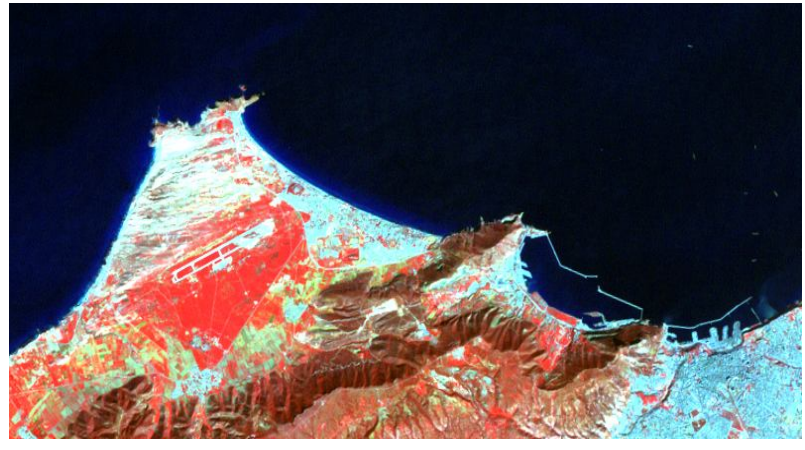

(b)

Figure 4: Images used, (a) synthetic image, (b) satellite image (themes are confusing)

For the satellite image, we started our application by loading the three images corresponding to the three channels.

At the end, a contrast enhancement was performed and then a colored composition by combining the blue filter with channel TM1, the green filter with channel TM3 and the red filter with channel TM4

The application of the SFLAvar proposed approach, like any population-based evolutionary algorithm, depends on several parameters such as population size $(\mu)$, number of communities (m), jump (R), fitness function (f) [17], etc. etc. For this we varied the size of the population, the number of communities and the number of individuals in each community as well as the frog jump and the number of iterations.

\subsection{Test 1}

The first test is to set the iteration number (it) to 1 and vary the frog jump (R), the number of community $m$ representing the maximum number of classes in the image as well as the size of the population $\mu$ which is the product of the number of communities and the number of individuals in each community.

The results obtained indicate the fitness functionas well as the necessary execution time and they are recorded in Tables 1.b and Table 2.b, and the corresponding images are illustrated in Tables 1.a and Table 2.a.

This test was applied to both synthetic and satellite images. 
Table 1.a: Result of synthetic image classification by SFLAvar, with IT=1, $\mu / m=(9 / 3,36 / 6,48 / 8)$, varying $R$ to $0.5,1$ and Rand.

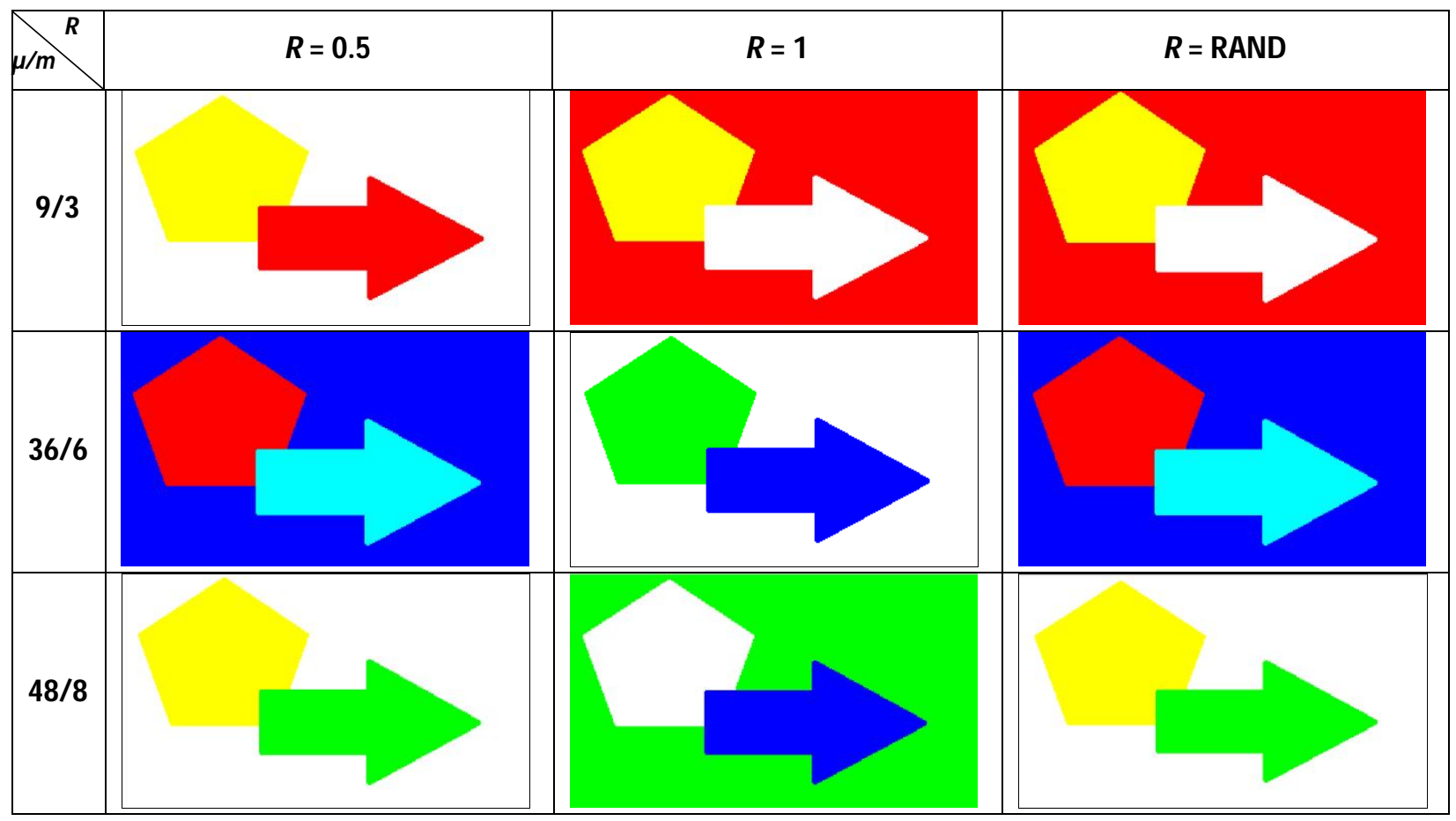

Table 1.b: Evaluation of synthetic image classification by SFLAvar, with it=1, $\mu / m=(9 / 3,36 / 6,48 / 8)$, varying $R$ to $0.5,1$ and Rand.

\begin{tabular}{|c|c|c|c|c|}
\hline \multirow{2}{*}{\multicolumn{2}{|c|}{$\mu / m$}} & \multirow[t]{2}{*}{$R=0.5$} & \multirow[t]{2}{*}{$R=1$} & \multirow[t]{2}{*}{$\mathbf{R}=\mathbf{R A N D}$} \\
\hline & & & & \\
\hline \multirow{2}{*}{$9 / 3$} & $\begin{array}{c}\text { Fitness } \\
\text { Fonction F }\end{array}$ & 0.8863 & 0.60410 & 0.8205 \\
\hline & $\begin{array}{c}\text { Execution } \\
\text { Time }\end{array}$ & 6.765 & 7.9837 & 6.1284 \\
\hline \multirow{2}{*}{$36 / 6$} & $\begin{array}{c}\text { Fitness } \\
\text { Fonction F }\end{array}$ & 1.08 & 0.93 & 0.9833 \\
\hline & $\begin{array}{c}\text { Execution } \\
\text { Time }\end{array}$ & 11.03 & 11.69 & 13.35 \\
\hline \multirow{2}{*}{$48 / 8$} & $\begin{array}{c}\text { Fitness } \\
\text { Fonction F }\end{array}$ & 0.9111 & 0.8884 & 0.9727 \\
\hline & $\begin{array}{c}\text { Execution } \\
\text { Time }\end{array}$ & 14.4821 & 15.5114 & 13.2384 \\
\hline
\end{tabular}


Table 2.a: Result of satellite image classification by SFLAvar, with $\mathrm{IT}=1, \mu / \mathrm{m}=(9 / 3,36 / 6,48 / 8)$, varying $\mathrm{R}$ to $0.5,1$ and $\mathrm{Rand}$.

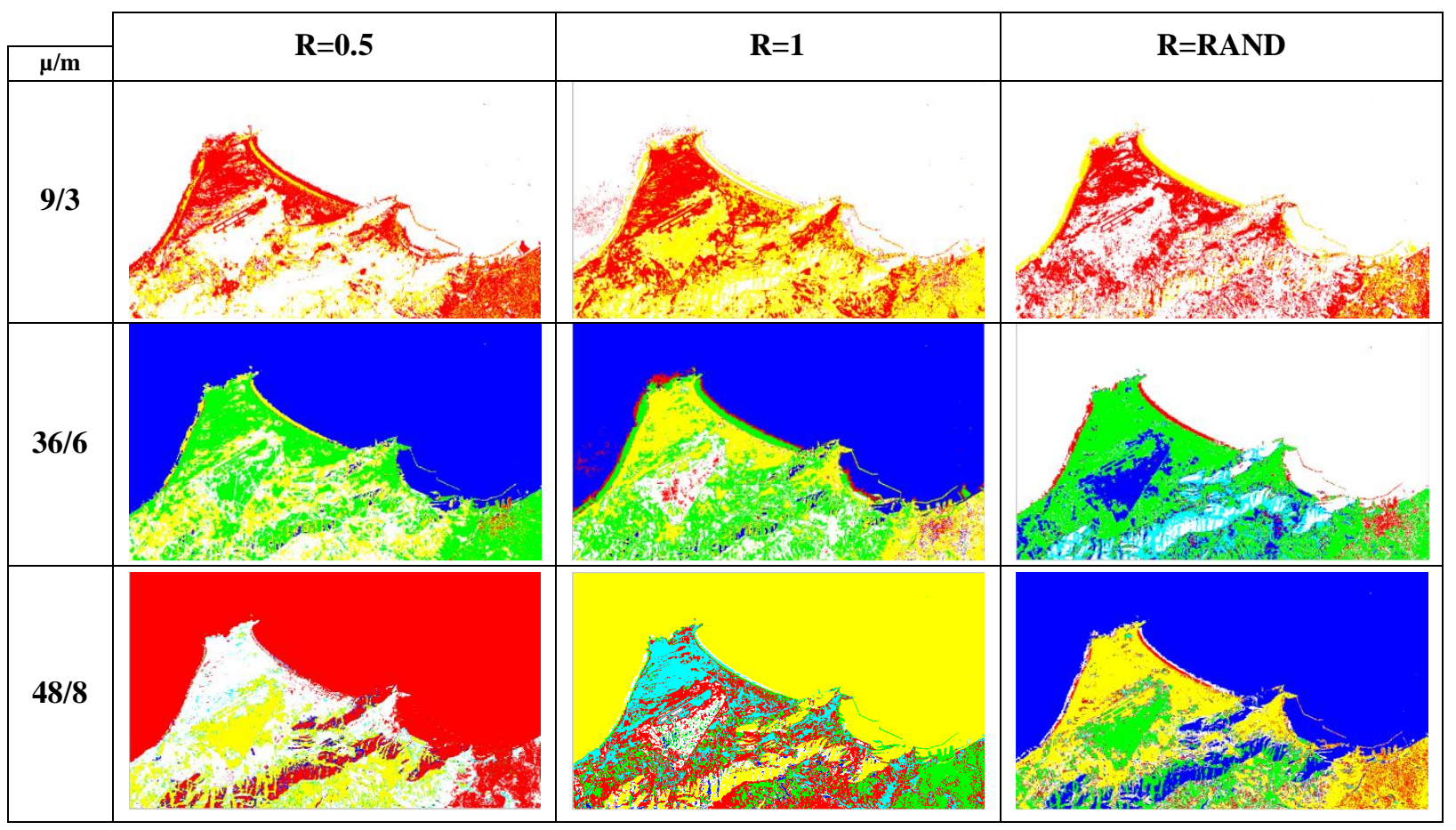

Table 2.b: Evaluation of satellite image classification by SFLAvar, with $\mathrm{IT}=1, \mu / \mathrm{m}=(9 / 3,36 / 6,48 / 8)$, varying $\mathrm{R}$ to $0.5,1$ and Rand

\begin{tabular}{|c|c|c|c|c|}
\cline { 5 - 5 } \multicolumn{2}{c|}{} & $\mathbf{R}=\mathbf{0 . 5}$ & $\mathbf{R}=\mathbf{1}$ & \multirow{2}{*}{ R=RAND } \\
\hline \multirow{3}{*}{$\mathbf{9 / 3}$} & $\begin{array}{c}\text { Fitness } \\
\text { Fonction F }\end{array}$ & 0,953728 & 0,94317 & 0,972575 \\
\cline { 2 - 5 } & $\begin{array}{c}\text { Execution } \\
\text { Time }\end{array}$ & 179,704485 & 171,3914 & 171,737521 \\
\hline \multirow{3}{*}{$\mathbf{3 6 / 6}$} & $\begin{array}{c}\text { Fitness } \\
\text { Fonction F }\end{array}$ & 0,8281 & 0,7228 & 0,7634 \\
\cline { 2 - 5 } & $\begin{array}{c}\text { Execution } \\
\text { Time }\end{array}$ & 216.357377 & 204,015984 & 204,82575 \\
\hline \multirow{3}{*}{$\mathbf{4 8 / 8}$} & $\begin{array}{c}\text { Fitness } \\
\text { Fonction } \mathbf{F}\end{array}$ & 0,73918 & 0,733328571 & 0,7738 \\
\cline { 2 - 5 } & $\begin{array}{c}\text { Execution } \\
\text { Time }\end{array}$ & 208,227674 & 251,503158 & 228,339308 \\
\hline
\end{tabular}

\subsection{Discussion of Test 1}

Based on the results indicated in tables 1 and 2, noting that:

By varying the frog jump $(\mathrm{R})$ to $\mathrm{R}=0.5, \mathrm{R}=1$ and $\mathrm{R}=\mathrm{RAND}$ (random value between 0 and 1 ) and, the best results were found to be satisfactory at $\mathrm{R}=1$ while a random value (RAND) of $R$ can cause divergence.

By varying the population/community size $(\mu / \mathrm{m})$, the results obtained show that a small population size generates a small diversity of the population; otherwise ( $\mu$ high) insignificant regions appear.

Other tests were carried out $(\mathrm{u} / \mathrm{m}=36 / 3,48 / 5,48 / 6,48 / 4)$ to evaluate this approach, which led us to conclude that there must be a balance between the number of individuals in each community.

It should be noted that the best results in terms of quality, execution time and objective function were achieved with $\mathrm{R}=1, \mu=36$ et $\mathrm{m}=6$ for both images. 
In the next tests $\mathrm{R}$ will be set to 1 .

\subsection{Test 2}

In this test we will use the same population/community parameters $(\mathrm{u} / \mathrm{m}=9 / 3,36 / 6,48 / 8)$ and we will vary the number of generations (iterations) IT to $1 ; 2 ; 3 ; 6 ; 10$ and 50 (with $\mathrm{R}=1$ ).

The results obtained are shown in Table 3.b and the corresponding images are shown in Table 3.a.

Table 3.a: Result of satellite image classification by sflavar, with $R=1, \mu / m=(9 / 3,36 / 6,48 / 8)$, varying IT to 1.2.3.6.10.

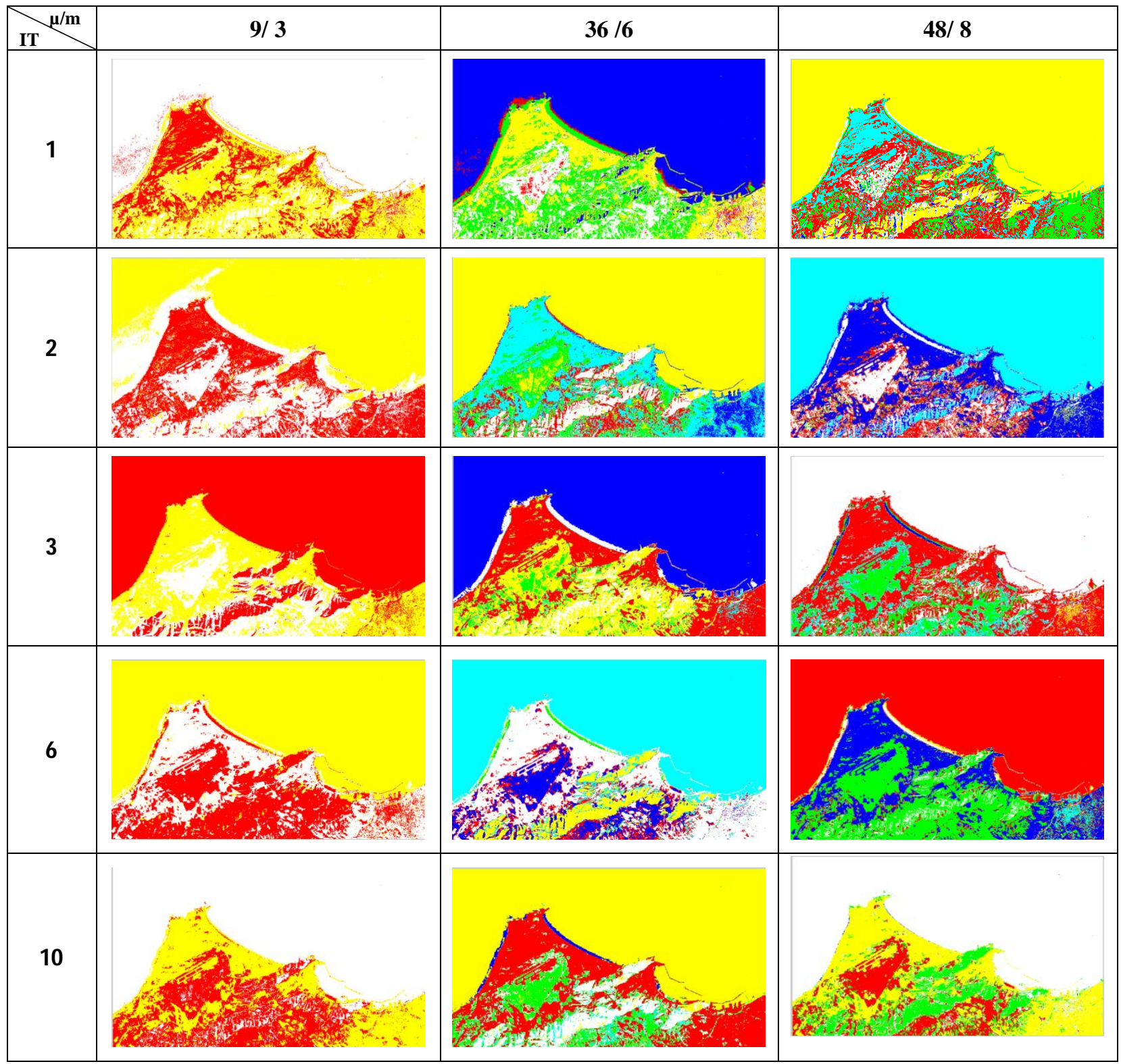


GHERDAOUI Sara et al., International Journal of Advanced Trends in Computer Science and Engineering, 11(1), January - February 2022, 34 - 41

Table 3.b: Assessment of satellite image classification by SFLAvar, with $\mathrm{R}=1, \mu / \mathrm{m}=(9 / 3,36 / 6,48 / 8)$, varying IT to 1.2 .3 .6 .10 .

\begin{tabular}{|c|c|c|c|c|}
\hline \multicolumn{2}{|c|}{${ }_{\text {IT }} \mu / \mathrm{m}$} & $9 / 3$ & $36 / 6$ & $48 / 8$ \\
\hline \multirow{2}{*}{ It $=1$} & $\begin{array}{c}\text { Fitness } \\
\text { Fonction } \mathbf{F}\end{array}$ & 0,94317 & 0,7228 & 0,733328571 \\
\hline & $\begin{array}{c}\text { Execution } \\
\text { Time }\end{array}$ & 171,3914 & 204,015984 & 251,503158 \\
\hline \multirow{2}{*}{$\mathrm{It}=\mathbf{2}$} & $\begin{array}{c}\text { Fitness } \\
\text { Fonction } \mathbf{F}\end{array}$ & 0.9442 & 0,668425 & 0,698966667 \\
\hline & $\begin{array}{c}\text { Execution } \\
\text { Time }\end{array}$ & 194,4713 & 222,023749 & 258,228484 \\
\hline \multirow{2}{*}{$\mathbf{I t}=\mathbf{3}$} & $\begin{array}{c}\text { Fitness } \\
\text { Fonction } \mathbf{F}\end{array}$ & 0.92031 & 0,659975 & 0,66363 \\
\hline & $\begin{array}{c}\text { Execution } \\
\text { Time }\end{array}$ & 201.54 & 239,012941 & 278,10997 \\
\hline \multirow{2}{*}{$\mathrm{It}=6$} & $\begin{array}{c}\text { Fitness } \\
\text { Fonction F }\end{array}$ & 0.91987 & 0,622475 & 0,6315875 \\
\hline & $\begin{array}{c}\text { Execution } \\
\text { Time }\end{array}$ & 219.601377 & 289,852953 & 321,724128 \\
\hline \multirow{2}{*}{ It $=10$} & $\begin{array}{c}\text { Fitness } \\
\text { Fonction } \mathbf{F}\end{array}$ & 0.9241 & 0,62601 & 0,633757143 \\
\hline & $\begin{array}{c}\text { Execution } \\
\text { Time }\end{array}$ & 243.21354 & 355,0377 & 402,551748 \\
\hline
\end{tabular}

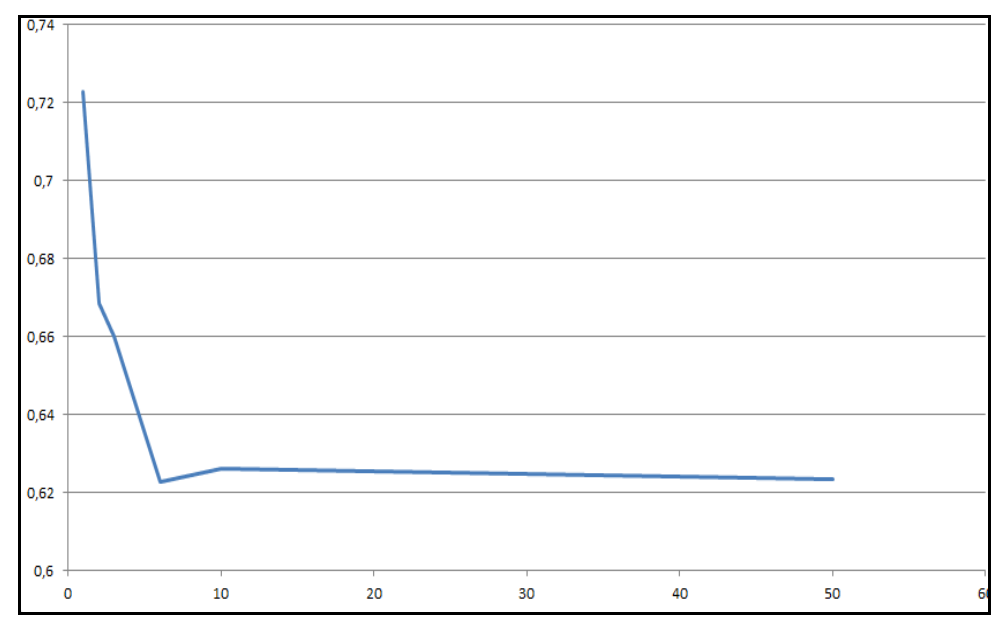

Figure 5: The evolution of the fitness function of the satellite image according to the number of iterations IT=50.

\subsection{Discussion of Test 2}

From the results obtained, shown in tables 3.a and 3.b, we can notice that the quality of the unsupervised classification of the image is satisfactory, the classes constituting the image have been well detected, however there is some confusion between classes, this is mainly due to the near radiometric value.

Figure 5. contains a graph showing the evolution of the fitness function of the satellite image during 50 iterations. From this graph, we note that our approach begins to converge from the third iteration and stabilizes from the 10th iteration.

By increasing the $\mu / \mathrm{m}$ combination to $48 / 8$ the algorithm was able to detect exactly the number of classes constituting the image Table 4 indicates the number of pixels in each class. 
Table 4. Number of affected pixels in each class making up the satellite image with $R=1, \mu / m=48 / 8$ and $I T=10$.

\begin{tabular}{|c|c|}
\hline $\begin{array}{c}\text { Classes constituting } \\
\text { the satellite image }\end{array}$ & Number of pixels \\
\hline Class 1 & 15658 \\
\hline Class 2 & 190343 \\
\hline Class 3 & 51157 \\
\hline Class 4 & 29100 \\
\hline Class 5 & 2281 \\
\hline Class 6 & 31461 \\
\hline Class 7 & 0 \\
\hline Class 8 & 0 \\
\hline
\end{tabular}

\section{CONCLUSION}

In this paper we developed a new SFLAvar approach for the unsupervised classification of satellite images based on the Shuffled Frog-Leaping Algorithm (SFLA) method and the operators of evolutionary algorithms variations.

The performance of the proposed approach depends on the appropriate selection of parameters (POPULATION SIZE, NUMBER OF COMMUNITIES, JUMP,). Notwithstanding the confusions observed, the results obtained were conclusive in terms of quality of classification and time of execution and objective function. Therefore it is suggested to integrate data other than the radiometric value such as texture, ground truths and multi-sensor images.

\section{REFERENCES}

[1] F.Y. Yang, P. Lohmann, and C. Heipke, Genetic Algorithms For Multi-Spectral Image Classification, Institute of Photogrammetry and GeoInformation, Leibniz, University of Hannover, springer, 2006.

[2] C. Ou and W. Lin, Comparison between PSO and GA for Parameters Optimization of PID Controller, 2006 International Conference on Mechatronics and Automation, 2006, pp. 2471-2475,

[3] M. Glickman, J.Balthrop, and S. Forrest, A Machine Learning Evaluation of an Artificial Immune System., Evolutionary Computation Journal, Vol 13, $\mathrm{n}^{\circ}$ 2, pp 179-212. 2005.

[4] C.M. Kim, M. Parnichkun, MLP, ANFIS, and GRNN based real-time coagulant dosage determination and accuracy comparison using full-scale data of a water treatment plant. J. Water Supply Res. Technol. 2016, Vol.66, pp.49-61.

[5] D. Tien Bui, M.M. Abdullahi and S. Ghareh, Fine-tuning of neural computing using whale optimization algorithm for predicting compressive strength of concrete. Engineering with Computers, vol. 37, pp. 701-712 (2021).

[6] S. Gherdaoui and H. Fizazi, La contribution des mouches à la classification des données satellitaires, in proc. Colloque Modélisation mathématique et informatique des systèmes complexes, Commisco 2010, France, Octobre 2010, pp. 17.

[7] H. Xie, L. Zhang, C.P. Lim, Y. Yu, H. Liu, Feature Selection Using Enhanced Particle Swarm Optimisation for Classification Models. Sensors 2021, Vol.21, 1816. https://doi.org/10.3390/s21051816

[8] A. Benyamina , H. Fizazi, AntClust adapté pour un partitionnement des images satellitaires par colonies de fourmis, Colloque sur l'Optimisation et les Systèmes d'Information COSI'2010, Ouargla, Algérie, Avril 2010.

[9] M.M. Eusuff, K.E. Lansey, Optimization of water distribution network design using the shuffled frog leaping algorithm. Planning Manag. vol. $129 \mathrm{n}^{\circ} 3$, pp. 210-225. 2003

[10] N. Ketfi, Contribution à la gestion des réseaux de distribution en présence de génération d'énergie dispersée. Ph.D, Department of Electrical Engineering, Faculty of Technology, University of Batna, 2014.

[11]E. Afzalan, M. A. Taghikhani and M. Sedighizadeh, Optimal Placement and Sizing of DG in Radial Distribution Networks Using SFLA, International Journal of Energy Engineering, Vol. 2, pp. 73-77, 2012.

[12]S. Gherdaoui, H. Fizazi, L'application de l'algorithme des grenouilles à la classification des données spatiales, 6th International Conference on Information Systems and New Technologies, Barcelona, ICIST' 2016 Spain. Mars 2016.

[13] M. Eusuff, K. Lansey, and F. Pasha, Shuffled frog-leaping algorithm: a memetic meta-heuristic for discrete optimization, Engineering Optimization, vol. 38, no. 2, pp. 129-154, 2006.

[14] B. Ashuri and M. Tavakolan, Shuffled frog-leaping model for solving time-cost-resource optimization problems in construction project planning, Journal of Computing in Civil Engineering, vol. 29, no. 1

[15] H. Moayedi, D. T. Bui, P. T. Ngo, Shuffled Frog Leaping Algorithm and Wind-Driven Optimization Technique Modified with Multilayer, Applied Sciences, vol. 10(2),689, 2020, doi:10.3390/app10020689

[16]S. Gherdaoui, H. Fizazi, Hybrid Approach for the Detection of Regions of a Satellite Image, IREASE, VOL 10, NO 3, 2017.

[17]B. Desgraupes, Clustering Indices, University Paris Ouest, Lab Modal'X, November 2017 